\title{
Characteristics and outcomes of secondary nodules identified on initial computed tomography scan for patients undergoing resection for primary non-small cell lung cancer
}

\author{
Brendon M. Stiles, MD, Michael Schulster, BA, Abu Nasar, MS, Subroto Paul, MD, Paul C. Lee, MD,
} Jeffrey L. Port, MD, and Nasser K. Altorki, MD

Objective: We sought to define the prevalence, malignancy rate, and outcome of secondary nodules (SNs) detected on computed tomography (CT) scan for patients undergoing resection for primary non-small cell lung cancer (NSCLC).

Methods: In consecutive patients with NSCLC, we reviewed all CT scan reports obtained at diagnosis of the dominant tumor for description of SNs. When resected, pathology was reviewed. Serial CT reports for 2 years postoperatively were evaluated to follow SNs not resected.

Results: Among 155 patients, $88(57 \%)$ were found to have SNs. A total of 137 SNs were evaluated (median size, $0.5 \mathrm{~cm})$. Thirty-two nodules were resected at primary resection. Nineteen $(61 \%)$ resected nodules were benign, whereas $13(39 \%$ ) were malignant ( 8 synchronous primary tumors and 5 lobar metastases). A total of 105 unresected nodules were followed by CT. Of these, $32(30 \%)$ resolved completely, $20(19 \%)$ shrunk, and $28(27 \%)$ were stable, whereas $11(11 \%)$ were lost to follow-up. Fourteen SNs $(13 \%)$ grew, of which 5 were found to be malignant, each a new primary. Overall 5-year survival was not different between patients with or without SNs $(67 \%$ vs $64 \% ; P=.88)$.

Discussion: The prevalence of SNs on CT scan in patients undergoing resection for primary NSCLC is high. Only a low proportion of SNs are ever found to be malignant, predominantly those on the ipsilateral side as the dominant tumor. The presence of SNs has no effect on survival. Patients with SNs, if otherwise appropriately staged, should not be denied surgical therapy. (J Thorac Cardiovasc Surg 2015;149:19-24)

See related commentary on pages $24-5$.

Physicians who treat lung cancer are confronted with myriad incidental findings on computed tomography (CT) scans performed to diagnose or characterize dominant lung nodules. It is common to simultaneously discover smaller, secondary nodules (SNs) in the ipsilateral or opposite lung. Although the prevalence of nodules found on CT scans has been well defined in populations of patients undergoing CT screening for lung cancer, it is unclear how many newly diagnosed lung cancer patients have SNs. ${ }^{1,2}$ One would perhaps expect the prevalence of nodules

\footnotetext{
From the Division of Thoracic Surgery, New York Presbyterian Hospital, Weill Cornell Medical College, New York, NY.

Disclosures: Authors have nothing to disclose with regard to commercial support.

Read at the 94th Annual Meeting of The American Association for Thoracic Surgery, Toronto, Ontario, Canada, April 26-30, 2014.

Received for publication April 28, 2014; revisions received Sept 2, 2014; accepted for publication Oct 6, 2014

Address for reprints: Brendon M. Stiles, MD, Division of Thoracic Surgery, Department of Cardiothoracic Surgery, Ste M404, Weill Cornell Medical College, 525 E 68th St, New York, NY 10065 (E-mail: brs9035@med.cornell.edu). $0022-5223 / \$ 36.00$

Copyright (C) 2015 Published by Elsevier Inc. on behalf of The American Association for Thoracic Surgery

http://dx.doi.org/10.1016/j.jtcvs.2014.10.057
}

found in patients with lung cancer to be higher than that of the general population and expect a higher rate of malignancy of these "incidental" nodules found in patients with lung cancer. Based on that assumption, concern arises that SNs detected on CT scan for primary non-small cell lung cancer may simply be thought to represent locally advanced or metastatic disease by treating or referring physicians. In this situation, patients could be denied potentially curative surgery. Understanding the frequency and the natural history of $\mathrm{SNs}$ is critical to provide appropriate surgical care for patients. It is therefore important to define the prevalence of SNs identified on CT scans for patients with primary lung cancer, to determine the rate of malignancy of SNs, and to determine whether SNs affect survival of patients undergoing resection for lung cancer.

\section{METHODS}

In a cohort of consecutive patients with non-small cell lung cancer undergoing resection in 2008, we reviewed all CT scan reports obtained at the time of the diagnosis of the dominant tumor (DT). The DT was defined as the nodule for which the primary workup and surgery were being performed. We purposefully chose a remote year to have adequate CT and survival follow-up. We then reviewed all CT reports for the mention of SNs. When available, images were reviewed. SNs were characterized by size, location, and CT characteristics. Nodules were documented to be characterized as either solid, part-solid (or part ground glass), or ground 


\section{Abbreviations and Acronyms \\ $\mathrm{CT}=$ computed tomography \\ DT $=$ dominant tumor \\ PET $=$ positron emission tomography \\ $\mathrm{SN}=$ secondary nodule}

glass (nonsolid). When resected, pathology of SN was reviewed and compared with the DT. Images and reports for 2 years postoperatively were evaluated to follow those SNs not resected. In particular, all CT scan images on which an $\mathrm{SN}$ was reported to grow or in which there was a discrepancy of SN location were evaluated. Surveillance CT reports were obtained at $6,12,18$, and 24 months, then yearly. Patient information was retrieved from a prospectively maintained thoracic surgery database. The Institutional Review Board of Weill Medical College and the New York-Presbyterian Hospital approved the database and the study design. Patient consent was waived. Demographic, clinical, and pathologic characteristics of patients with and without SNs were compared. Predictors of malignancy in SNs were evaluated by univariate analysis, with significant predictors $(P<.20)$ incorporated into a multivariate model. Overall survival was analyzed using the Kaplan-Meier method. Differences in survival were compared using the log-rank test. Follow-up is updated in our clinical database every 6 months.

\section{RESULTS}

Among 155 patients undergoing resection for primary lung cancer in 2008, 88 patients $(57 \%)$ were found to have SNs (Figure 1). Patients with SNs were more likely to have smoked tobacco $(81 \%$ vs $72 \% ; P=.044)$. Patients with SNs had no significant differences in age, gender, or DT histology compared with patients without SNs (Table 1). There were no differences between groups regarding comorbidities or forced expiratory volume in 1 second. The majority of patients $(\mathrm{n}=105 ; 68 \%)$ had a positron emission tomography (PET) scan as part of their clinical workup. Another 53 patients (34\%) underwent mediastinoscopy before resection. There was no difference in PET or mediastinoscopy use in patients with and without SNs. The majority of patients in each group underwent anatomic resection of their primary tumors $(90 \%$ for patients with $\mathrm{SNs}$ vs $85 \%$ for those without; $P=.396$ ). The incidence of nodal metastases and the final pathologic stages were also not significantly different between the groups as a whole (Table 1).

Among 88 patients with SNs, 11 were identified as having scattered nodules not distinguished individually on CT reports. These were excluded from follow-up studies due to our inability to explicitly compare them on follow-up CT scans. In the remaining 77 patients with positive CTs, we identified 137 nodules (1.8 nodules per patient) (Table 2). The mean and median size of the SN was $0.62 \mathrm{~cm}$ and $0.5 \mathrm{~cm}$, respectively (range, $0.1-2.7 \mathrm{~cm}$ ). Sixty-seven SNs $(49 \%)$ were ipsilateral, including 26 $(19 \%)$ in the same lobe as the DT, whereas $70(51 \%)$ were contralateral. By CT reports, $105 \mathrm{SNs}(77 \%)$ were characterized as solid, $11(8 \%)$ were part-solid, and 21 $(15 \%)$ were characterized as ground-glass opacities.

Among patients with additional nodules, 119 of 137 SNs were further evaluated by PET scan. The remaining 18 nodules were present in patients who did not receive PET scans. Of the 119 SNs, 14 were reported as PET positive (any reported maximum standardized uptake value greater than background) with a mean and median maximum standardized uptake value of 3.5 and 1.75 , respectively. Of these, $10 \mathrm{SNs}$ were solid, 1 was part-solid, and 3 were ground-glass opacities. The mean and median size of PET-positive SNs was $1.2 \mathrm{~cm}$ and $1.1 \mathrm{~cm}$, respectively.

Thirty-one nodules were resected at the time of primary resection, of which most $(n=22 ; 71 \%)$ were in the same lobe as the primary tumor. The majority of the resected nodules $(\mathrm{n}=19 ; 61 \%)$ were benign, whereas $12(39 \%)$ were malignant (Table 3). One other contralateral nodule judged to be a synchronous primary tumor was resected 4 months later as a staged resection. Of 13 total malignant nodules, 8 were thought to be distinct primary tumors, whereas 5 were thought to have similar histology to the DT. Eight malignant nodules resected initially were in the same lobe as the primary tumor.

A total of 105 unresected nodules were followed by CT (median CT follow-up was 25 months). The fate of those nodules is demonstrated in Figure 1. Two-thirds did not grow. Of those, $32 \mathrm{SNs}$ resolved completely (30\%), 20 SNs shrunk (19\%), and 28 SNs were stable $(27 \%)$ over time. Eleven patients with SNs $(11 \%)$ were lost to CT follow-up. Fourteen nodules (13\%) grew, of which only 5 $(4.8 \%$ of total) were found to be malignant, each a new primary adenocarcinoma. Three new cancers were ipsilateral, whereas 2 were contralateral. The 9 additional nodules had only minimal growth on CT and were assumed to be benign, although 1 patient died from undocumented causes and was therefore lost to further CT follow-up.

The overall rate of malignant $\mathrm{SN}$ was low in our series $(n=18$ out of $137 ; 13 \%)$. In particular the rate of SNs found to be metastases from the DT was only $3.6 \%$ (5 out of 137). In patients found to have SN in the same pulmonary lobe as the DT, the rate of malignancy was $36 \%$. We analyzed the data to determine predictors of malignancy in the $\mathrm{SN}$, excluding those patients $(\mathrm{n}=11)$ with scattered nodules (Table 3). By multivariate analysis, location of the SN on the ipsilateral side as the DT (odds ratio [OR], 5.77; $95 \%$ confidence interval [CI], 1.16-28.72) and SN size (continuous variable OR, 5.16; 95\% CI, 1.46-18.21) were the most important predictors of malignancy for SNs. Smoking history, CT characteristics, and node status were not predictors of malignancy in SNs. We performed a second analysis on only ipsilateral SNs $(n=67)$, because the decision regarding whether or not to remove them at 


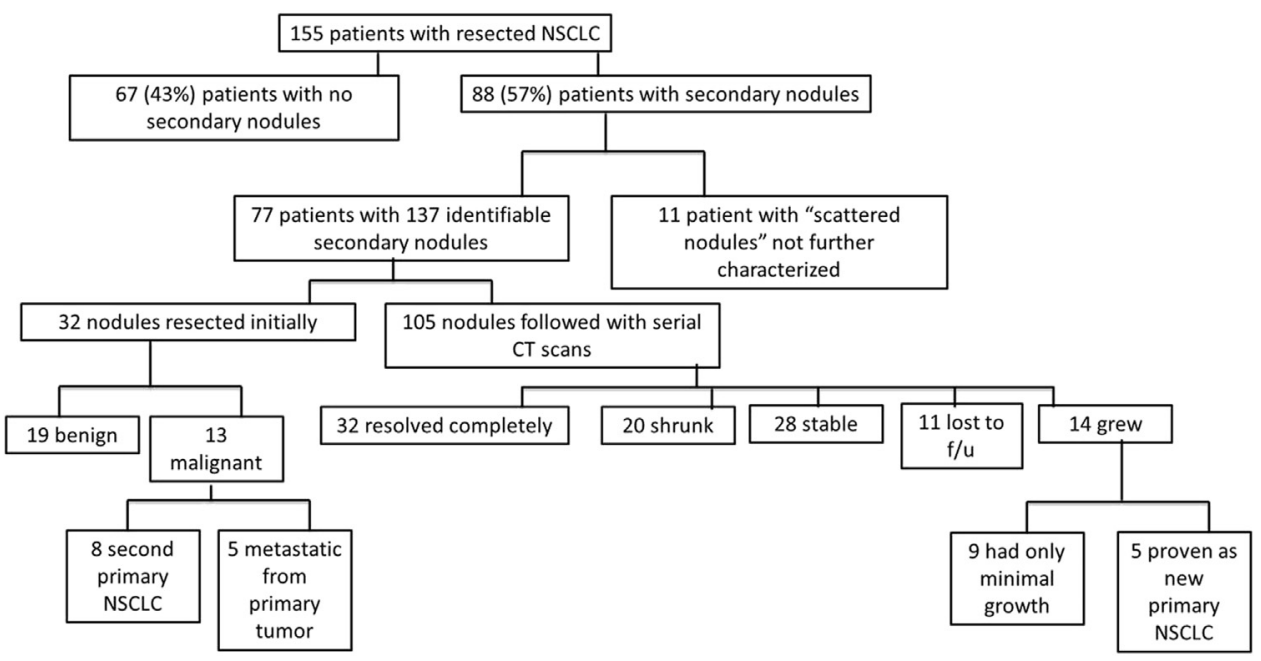

FIGURE 1. Tree depicting outcomes of secondary nodules found in consecutive patients undergoing lung cancer resection. Secondary nodules not resected at the surgery for the primary lung tumor were followed by serial computed tomography $(C T)$ scans. NSCLC, Non-small cell lung cancer.

the time of operation may be more relevant. On multivariate analysis, location in the same lobe as the primary tumor (vs other ipsilateral lobes) predicted malignancy (OR, $11.82 ; 95 \% \mathrm{CI}, 1.17-119.7)$ as did size of the ipsilateral SN (OR, 12.96; 95\% CI, 1.76-95.2).

At a median follow-up of 56 months, overall 5-year survival was not different among all patients with or without SNs $(67 \%$ vs $64 \% ; P=.88$ ) (Figure 2 ) or among stage patients with IA disease with or without SNs $(76 \%$ vs $79 \% ; P=.94)$. In a univariate model, the presence of SNs was not predictive of mortality (hazard ratio, 1.06; $95 \%$ CI, $0.53-2.14 ; P=.87)$ in this cohort of patients with lung cancer.

\section{DISCUSSION}

The identification of secondary lung nodules on CT scans of patients undergoing resection for lung cancer is a common occurrence. In our series of consecutive patients undergoing lung cancer resection during 1 year, $57 \%$ of patients had nodules other than the primary tumor reported on their initial CT scans. Such nodules may pose a clinical dilemma because they could represent benign disease, metastasis from the primary tumor, or synchronous primary lung cancers. ${ }^{3}$ Little is known about the natural history of these nodules in patients with lung cancer, despite a wealth of information regarding follow-up of screen-detected lung nodules in patients without a primary lung cancer diagnosis. ${ }^{1,2,4}$ In that patient population, the incidence of cancer in detected nodules is exceedingly low, on the order of only $3.8 \%$ in the National Lung Screening Trial. ${ }^{1}$ However, it could perhaps be expected that patients with newly diagnosed lung cancer would have higher rates of malignant SNs, either due to spread of the primary tumor or due to genetic or field effects predisposing these patients to synchronous primary cancers. ${ }^{3,5-8}$ It is critical for both referring physicians and thoracic surgeons to understand the frequency of $\mathrm{SNs}$ and to determine the rate of malignancy in such nodules. Among referring physicians, it is conceivable that some patients with $\mathrm{SN}$ at diagnosis may be presumed to have locally advanced or metastatic disease and could be denied potentially curative surgical therapy. For surgeons, understanding which SNs have the highest likelihood of malignancy may help to tailor diagnostic and surgical approaches.

In our series there were no clinical characteristics that distinguished patients with SNs from those without. Larger screening studies have demonstrated female gender, older age, and the presence of emphysema to be clinical predictors of malignancy. ${ }^{2}$ It is likely that our study was not large enough to detect such distinctions. In our patients there was a relatively equal distribution of SNs on the ipsilateral $(49 \%)$ and contralateral $(51 \%)$ sides from the primary tumor, although $\mathrm{SN}$ on the ipsilateral side as the DT were significantly more likely to be diagnosed as malignant. The majority of nodules described by radiologists were solid $(77 \%)$, very similar to rates $(79 \%-80 \%)$ of nodules found in large screening trials. ${ }^{2}$ Only a minority of the nodules were PET positive, but uptake on the PET predicted malignancy on univariate, although not on multivariate, analysis. Not surprisingly, SN size was an important predictor of malignancy. The median size of SNs diagnosed as malignant was $1.1 \mathrm{~cm}$ compared with $0.4 \mathrm{~cm}$ for those believed to be benign $(P<.001)$.

In planning operative strategies for patients with lung cancer with SNs, the surgeon must decide if an attempt should be made to resect the SN identified on the CT scan, particularly in the case of ipsilateral nodules. Of nodules resected at the time of the surgery for the DT, $39 \%$ were malignant, a much higher rate than that 
TABLE 1. Patient demographics among patients diagnosed with lung cancer without and with secondary nodules

\begin{tabular}{|c|c|c|c|}
\hline & $\begin{array}{c}\text { Without } \\
\text { secondary } \\
\text { nodules } \\
(n=67) \\
\end{array}$ & $\begin{array}{c}\text { With secondary } \\
\text { and scattered } \\
\text { nodules } \\
(\mathbf{n}=\mathbf{8 8})\end{array}$ & $\begin{array}{c}P \\
\text { value }\end{array}$ \\
\hline Age, y & $66(56-74)$ & $68(61-77)$ & .146 \\
\hline \multicolumn{4}{|l|}{ Gender } \\
\hline Female & $37(55)$ & $55(64)$ & \multirow[t]{2}{*}{.361} \\
\hline Male & $30(45)$ & $33(38)$ & \\
\hline \multicolumn{4}{|l|}{ Smoking status } \\
\hline Never & $19(28)$ & $17(19)$ & \multirow[t]{3}{*}{.044} \\
\hline Current & $18(27)$ & $14(16)$ & \\
\hline Former & $30(45)$ & $57(65)$ & \\
\hline \multicolumn{4}{|l|}{ Comorbidities } \\
\hline $\begin{array}{l}\text { Coronary artery disease or } \\
\text { myocardial infarction }\end{array}$ & $9(13)$ & $16(18)$ & .426 \\
\hline $\begin{array}{l}\text { Chronic obstructive pulmonary } \\
\text { disease or emphysema }\end{array}$ & $8(12)$ & $11(12)$ & .916 \\
\hline Diabetes & $10(15)$ & $10(11)$ & .512 \\
\hline Stroke & $2(3)$ & $3(3)$ & .999 \\
\hline $\begin{array}{l}\text { Forced expiratory volume } \\
\text { in } 1 \text { second }\end{array}$ & $88(78-103)$ & $87(74-98)$ & .309 \\
\hline \multicolumn{4}{|l|}{ Histology } \\
\hline Invasive adenocarcinoma & $41(61)$ & $62(71)$ & \multirow[t]{4}{*}{.408} \\
\hline Adenocarcinoma in situ & $3(5)$ & $1(1)$ & \\
\hline Squamous cell carcinoma & $11(16)$ & $14(16)$ & \\
\hline Other & $12(18)$ & $11(12)$ & \\
\hline \multicolumn{4}{|l|}{ Differentiation } \\
\hline Well & $5(9)$ & $14(17)$ & \multirow[t]{4}{*}{.344} \\
\hline Moderate & $37(65)$ & $46(56)$ & \\
\hline Poor & $15(26)$ & $22(27)$ & \\
\hline Not specified & $10(15)$ & $6(6.8)$ & \\
\hline \multicolumn{4}{|l|}{ Pathologic stage } \\
\hline IA-IB & $48(72)$ & $55(63)$ & \multirow[t]{4}{*}{.561} \\
\hline IIA-IIB & $7(10)$ & $16(18)$ & \\
\hline IIIA-IIIB & $10(15)$ & $14(16)$ & \\
\hline IV & $2(3)$ & $3(3)$ & \\
\hline \multicolumn{4}{|l|}{ Pathologic T stage } \\
\hline Tis/T1 & $36(54)$ & $55(63)$ & \multirow[t]{4}{*}{.022} \\
\hline $\mathrm{T} 2$ & $27(40)$ & $18(20)$ & \\
\hline $\mathrm{T} 3$ & $3(5)$ & $9(10)$ & \\
\hline $\mathrm{T} 4$ & $1(1)$ & $6(7)$ & \\
\hline \multicolumn{4}{|l|}{ Pathologic N status } \\
\hline NX/N0 & $52(78)$ & $67(76)$ & \multirow[t]{2}{*}{.830} \\
\hline $\mathrm{N}+$ & $15(22)$ & $21(24)$ & \\
\hline \multicolumn{4}{|l|}{ Procedure types } \\
\hline Wedge & $10(15)$ & $9(10)$ & \multirow[t]{4}{*}{.396} \\
\hline Segmentectomy & $3(4)$ & $6(7)$ & \\
\hline Lobectomy/bilobectomy & $51(76)$ & $71(81)$ & \\
\hline Pneumonectomy & $3(4)$ & $2(2)$ & \\
\hline \multicolumn{4}{|l|}{ Mortality } \\
\hline Operative/30-d mortality & $0(0)$ & $1(1)$ & .999 \\
\hline
\end{tabular}

demonstrated in nodules that were followed over time $(4.8 \%)$. The higher rate of malignancy in resected nodules suggests some element of surgical judgment was involved
TABLE 2. Characteristics of secondary nodules (SNs) distinctly identified on computed tomography (CT) scan

\begin{tabular}{lc}
\hline \multicolumn{1}{c}{ Total nodules } & 137 (1.8/patient) \\
\hline SN size, cm & $0.62 \pm 0.45$ \\
Location & \\
$\quad$ Ipsilateral same lobe & $26(19 \%)$ \\
$\quad$ Ipsilateral different lobe & $41(30 \%)$ \\
$\quad$ Contralateral & $70(51 \%)$ \\
CT characteristic & \\
$\quad$ Solid & $105(77 \%)$ \\
Part-solid & $11(8 \%)$ \\
$\quad$ Ground-glass opacity & $21(15 \%)$ \\
Positron emission tomography uptake* & \\
$\quad$ Positive & $14(10 \%)$ \\
$\quad$ Maximum standardized uptake value & $3.5 \pm 5.2$ \\
$\quad$ of positive nodules & \\
\hline
\end{tabular}

$\overline{\text { Values are presented as mean } \pm \text { standard deviation or } \mathrm{n}(\%) \text {. CT, Computed tomog- }}$ raphy; $S N$, secondary nodule. *One hundred nineteen nodules only.

in deciding which nodules to resect, although this was difficult to accurately discern from our records. In particular, the rate of malignancy was $50 \%$ (5 out of 10 nodules) in SNs resected from lobes other than that containing the DT (including 1 patient undergoing staged operation for a contralateral nodule). Even for SNs in the same lobe as the DT, the rate of malignancy was relatively high $(36 \% ; 8$ out of 22 nodules), suggesting that limited resection should be undertaken with caution in patients with same-lobe SNs. In general, we would therefore favor lobectomy for any patients with an $\mathrm{SN}$ in the same lobe as the DT, assuming adequate pulmonary function. Our group has previously demonstrated good survival for this cohort of patients, particularly if node negative. ${ }^{6}$ For ipsilateral SNs in distinct lobes from the DT, we consider wedge resection if peripheral and palpable or segmentectomy, particularly for those SNs with risk factors for malignancy, including larger size and PET positivity. In general, we try to avoid lobectomy for these small, relatively low-risk nodules.

We carefully follow nodules not resected at the time of surgical therapy with serial CT scans. In our study, the overwhelming majority $(69 \%)$ resolved, shrunk, or stayed the same size. Most nodules that grew only demonstrated minimal growth $(1 \mathrm{~mm})$ and never required further workup. Only $4.8 \%$ of followed SNs grew and were subsequently diagnosed as cancer, all as distinct primary tumors. This percentage is remarkably similar to the rate of malignancy found in screen-detected nodules in at-risk patients. ${ }^{1,2}$

The rate of SN detected on initial CT scans for dominant lung tumors referred for surgical consideration is high, with $>50 \%$ of patients having such nodules. The rate of malignancy in these nodules is low, with only $13 \%$ of total SNs in our series demonstrated as cancer. In particular, the 
TABLE 3. Predictors of malignancy in secondary nodules

\begin{tabular}{|c|c|c|c|c|}
\hline \multirow[b]{2}{*}{ Independent variables } & \multicolumn{2}{|c|}{ Univariate predictors } & \multicolumn{2}{|c|}{ Multivariate predictors* } \\
\hline & OR $(95 \%$ CI $)$ & $P$ value & OR $(95 \%$ CI $)$ & $P$ value \\
\hline Age, y & $0.99(0.94-1.06)$ & .933 & & \\
\hline \multicolumn{5}{|l|}{ Gender } \\
\hline Male & Reference & .907 & & \\
\hline Female & $1.08(0.32-3.65)$ & & & \\
\hline \multicolumn{5}{|l|}{ Smoking status } \\
\hline Never & Reference & & & \\
\hline Current & $1.02(0.15-6.86)$ & .982 & & \\
\hline Former & $0.81(0.20-3.24)$ & .768 & & \\
\hline \multicolumn{5}{|c|}{ Computed tomography characteristics } \\
\hline Solid & Reference & & & \\
\hline Part-solid & $2.37(0.44-12.69)$ & .313 & & \\
\hline Ground glass opacity & $1.78(0.44-7.21)$ & .421 & & \\
\hline \multicolumn{5}{|l|}{ Number of secondary nodules } \\
\hline 1 & Reference & & & \\
\hline$>1$ & $1.21(0.36-4.08)$ & .765 & & \\
\hline \multicolumn{5}{|c|}{ Positron emission tomography status } \\
\hline Negative & Reference & & & \\
\hline Positive & $6.79(1.87-24.60)$ & .004 & $2.43(0.46-12.84)$ & .295 \\
\hline \multicolumn{5}{|l|}{ Location } \\
\hline Contralateral & Reference & & & \\
\hline Ipsilateral & $7.42(1.59-34.55)$ & .011 & $5.77(1.16-28.72)$ & .033 \\
\hline \multicolumn{5}{|l|}{ Size of secondary nodule } \\
\hline Nodule size, $\mathrm{cm}$ & $8.07(2.68-24.28)$ & $<.001$ & $5.16(1.46-18.21)$ & .011 \\
\hline \multicolumn{5}{|l|}{ Node status (pathologic stage) } \\
\hline Positive (N1-N2) & Reference & & & \\
\hline Negative (N0) & $1.52(0.40-5.76)$ & .540 & & \\
\hline
\end{tabular}

likelihood that these $\mathrm{SN}$ represent metastatic disease is exceedingly low. In our cohort, only 5 of $137 \mathrm{SNs}(3.6 \%)$ were pathologically consistent with spread from the primary tumor. Our data strongly suggest that patients with SNs should not be denied surgical consultation or therapy. The choice of resection of the SN at the time of

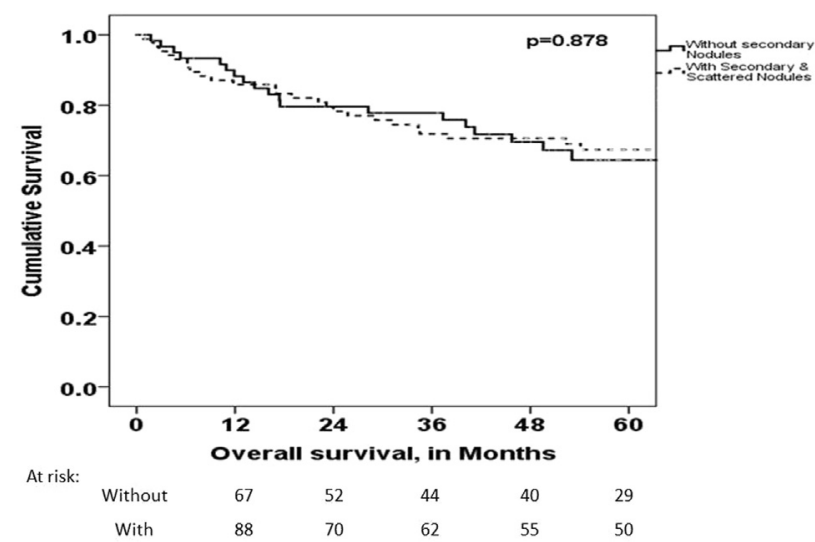

FIGURE 2. Overall survival of patients with secondary nodules, isolated or scattered $(n=88)$ versus patients without secondary nodules $(n=67)$ on initial computed tomography scans for primary lung cancer. the initial surgery for the DT should be at the discretion of the surgeon, but may be influenced by factors such as $\mathrm{SN}$ location and size. For nodules not resected at the time of surgery, the natural history appears to be similar to that of CT-detected nodules. In our series, only $4.8 \%$ of SNs followed with serial CT scans were subsequently diagnosed as lung cancer. This information is useful to reassure patients who are understandably concerned about the possibility of cancer spread or recurrence based on a review of their radiology reports.

Our study has some distinct limitations. It is possible that some patients in the community with multiple SNs believed to represent metastatic disease or multiple primary tumors were not referred to us, limiting the proportion of SNs that were found to have malignancy in our practice. However, by reporting on consecutive lung cancer patients rather than on a hand-picked population of patients with SNs, we believe that we reliably captured a clinically relevant incidence of SNs. Our study is also limited by its retrospective nature and by the reliance upon $\mathrm{CT}$ reports dictated by radiologists to identify $\mathrm{SNs}$ and define characteristics and growth over time. The thought process and decision making of the surgeon with regard to SNs could not be adequately accounted for in our retrospective 
review. However, by relying on the $\mathrm{CT}$ reports as documented and sent to referring physicians, we believe that our method is clinically relevant to referring physicians who must decide whether to refer these patients for surgical or oncologic evaluations and to surgeons who must decide what to do with these SNs.

\section{References}

1. The National Lung Screening Trial Research Team, Aberle DR, Adams AM, Berg CD, Black WC, Clapp JD, Fagerstrom RM, et al. Reduced lung-cancer mortality with low-dose computed tomographic screening. N Engl J Med. 2011;365:395-409. 2. McWilliams A, Tammemagi MC, Mayo JR, Roberts H, Liu G, Soghrati K, et al. Probability of cancer in pulmonary nodules detected on first screening CT. N Engl J Med. 2013;369:910-9.
3. Martini N, Melamed MR. Multiple primary lung cancers. J Thorac Cardiovasc Surg. 1975;70:606-12.

4. The National Lung Screening Trial Research Team, Church TR, Black WC, Aberle DR, Berg CD, Clingan KL, Duan F, et al. Results of initial low-dose computed tomographic screening for lung cancer. N Engl J Med. 2013;368: 1980-91.

5. Adebonojo SA, Moritz DM, Danby CA. The results of modern surgical therapy for multiple primary lung cancers. Chest. 1997;112:693-701.

6. Port JL, Korst RJ, Lee PC, Kansler AL, Kerem Y, Altorki NK. Surgical resection for multifocal (T4) non-small cell lung cancer: is the T4 designation valid? Ann Thorac Surg. 2007;83:397-400.

7. Lee BE, Port JL, Stiles BM, Saunders J, Paul S, Lee PC, et al. TNM stage is the most important determinant of survival in metachronous lung cancer. Ann Thorac Surg. 2009;88:1100-5.

8. Finley DJ, Yoshizawa A, Travis W, Zhou Q, Seshan VE, Bains MS, et al. Predictors of outcomes after surgical treatment of synchronous primary lung cancers. J Thorac Oncol. 2010;5:197-205.

\section{EDITORIAL COMMENTARY}

\section{The prevalence and fate of secondary nodules found in patients undergoing resection for lung cancer}

Thomas Ng, MD

See related article on pages 19-24.

Thoracic surgeons have long dealt with secondary nodules found on initial imaging in patients being evaluated for resection of lung cancer. Patients who are deemed surgical candidates are often given "the benefit of the doubt," when surgeons consider these secondary nodules to be either benign or second primary, rather than metastatic, and proceed with the planned resection. Due to the lack of data supporting this practice, whether other medical specialists share this point of view is unknown, as is the number of patients who are not referred for surgical evaluation on the presumption that such secondary nodules represent metastatic disease. Herein lies the importance of the article by Stiles and colleagues ${ }^{1}$ in this month's Journal of Thoracic and Cardiovascular Surgery. The results of this study confirm what thoracic surgeons have long suspected: secondary nodules are common; only a small proportion are metastatic; and surgery should not be denied for an

From the Department of Surgery, The Warren Alpert Medical School of Brown University, Providence, RI.

Disclosures: Author has nothing to disclose with regard to commercial support.

Received for publication Oct 18, 2014; accepted for publication Oct 18, 2014.

Address for reprints: Thomas Ng, MD, 2 Dudley St, Suite 470, Providence, RI 02905

(E-mail: tng@usasurg.org).

J Thorac Cardiovasc Surg 2015;149:24-5

$0022-5223 / \$ 36.00$

Copyright (c) 2015 by The American Association for Thoracic Surgery

http://dx.doi.org/10.1016/j.jtcvs.2014.10.089 otherwise good operative candidate, owing to the presence of secondary nodules.

The prevalence of nodules or a "positive" initial scan, reported by the National Lung Screening Trial, ${ }^{2}$ was $27 \%$, with $3.8 \%$ of these nodules ultimately determined to be malignant. The higher prevalence found by Stiles and colleagues, ${ }^{1}$ of $57 \%$ of secondary nodules, is therefore not surprising, as the cohort studied represents a subset of even higher-risk patients-those already diagnosed with lung cancer. Ultimately, $13 \%$ of these secondary nodules were determined to be malignant, with $9.5 \%$ being second primary lung cancer, and only $3.6 \%$ being metastatic from the dominant nodule or cancer, with all metastatic nodules being ipsilateral in location. Overall survival was not different between patients with and without the presence of secondary lung nodules seen on initial scan, likely because of the small percentage of secondary nodules that represented metastatic disease.

In addition, Stiles and colleagues ${ }^{1}$ performed multivariate analysis for factors associated with a malignant secondary nodule, the results of which were not unexpected. When both ipsilateral and contralateral secondary nodules were considered, size and laterality were associated with malignancy. When only ipsilateral secondary nodules were considered, size and location (within the same lobe) were associated with malignancy. In the final analysis, the most important result presented by Stiles and colleagues ${ }^{1}$ seems to be the fact that, despite the high prevalence of secondary nodules found in patients presenting for lung 